\title{
Effectiveness and the quality of life following laparoscopic Burch colposuspension for genuine urinary stress incontinence: six and twelve months follow up
}

\author{
D Silva ${ }^{a}$, S Samarakkodi ${ }^{b}$, M Rajakaruna $^{c}$, S Adeesha ${ }^{d}$, R Edirisinghe ${ }^{e}$
}

\begin{abstract}
Overview: Burch colposuspension is introduced in 1961 and since then it has been the gold standard treatment modality for genuine urinary stress incontinence.

Methods: In this prospective cross-sectional study we have analyzed data from 36 women aged 42 to 63 years who had undergone laparoscopic Burch colposuspension at Colombo South Teaching Hospital Sri Lanka during the period from 2012 to 2021. Patients completed a self-administered Short Urinary Distress Inventory (SUDI) and Short Incontinence Impact Questionnaire (SIIQ) at both the baseline and the post-operative follow up (6 months, 12 months) period. The Genito-Urinary Treatment Satisfaction Scale (GUTSS) was utilized to assess satisfaction with the outcomes of the laparoscopic repair surgery.

Results: Six months following the surgery, Stress Urinary Incontinence (SUI) was $9.38 \%$ with $p=0.38$, SUI and/or urge incontinence was $18.75 \%$ with $p=0.56$, which were statistically not significant. In both analyses of SUDI and SIIQ there were significant improvements in outcomes. Satisfaction with treatment outcomes from the GUTSS at six months follow up was $32.5 \pm 5.8$ with $p=0.48$. At 12 months following surgery, $15.6 \%$ of patients had GSI while $9.38 \%$ had stress incontinence frequently $(p=0.26)$.

Conclusion: Laparoscopic Burch colposuspension is an effective technique and treatment modality for urinary stress incontinence. Both objective and subjective evaluation of surgical outcomes at 6 and 12 months of follow-up demonstrated significant improvement and repetitive corrective surgeries are uncommon.
\end{abstract}

Sri Lanka Journal of Obstetrics and Gynaecology 2021; 43: 284-291

DOI: http://doi.org/10.4038/sljog.v43i4.8009

a Professor in Obstetrics and Gynaecology, Senior Lecturer, Faculty of Medical Sciences, University of Sri Jayewardenepura, Sri Lanka

b Senior Registrar in Obstetrics and Gynaecology, Colombo, South Teaching Hospital, Kalubowila, Sri Lanka

c Senior Registrar in Obstetrics and Gynaecology, Colombo, South Teaching Hospital, Kalubowila, Sri Lanka

${ }^{\mathrm{d}}$ Registrar in Obstetrics and Gynaecology, Colombo South Teaching, Hospital, Kalubowila, Sri Lanka

e Released House Officer in Obstetrics and Gynaecology, Colombo South Teaching Hospital, Kalubowila, Sri Lanka

Correspondence: DS, e-mail: dhammikesilva@gmail.com

(D) https://orcid.org/0000-0003-1800-6737

Received 28 ${ }^{\text {th }}$ August 2021

Accepted 24 $4^{\text {th }}$ January 2022 


\section{Introduction and background}

Stress urinary incontinence (SUI) is defined as involuntary leakage of urine on exertion or on coughing ${ }^{1}$ or sneezing by the International Continence Society. It is a common but debilitating problem to the affected individuals with regard to their quality of life (QOL). In developed and resource-rich countries, the prevalence of SUI has been assessed in adult women as $17-45 \%{ }^{2}$. A cross-sectional Norwegian study (involving 15,308 women, aged $<65$ years) showed that the prevalence of SUI was $4.7 \%$ in women who are nulliparous, $6.9 \%$ in women who have had caesarean deliveries only, and $12.2 \%$ in women who have had vaginal deliveries only ${ }^{3}$.

There are several causes and pathophysiological mechanisms explained in the literature. Urethral hypermobility along with relaxed pelvic floor muscles and poor pelvic floor support and intrinsic urethral sphincter dysfunction at the bladder neck due to the defective smooth muscle mechanism of the sphincter where closure is inefficient, are a few pathophysiological factors that give rise to $\mathrm{USI}^{4}$. Number of surgical as well as non-surgical treatment modalities have been pronounced to correct the stress urinary incontinence ${ }^{5}$. The Burch colposuspension is a reliable surgical management option for SUI caused by urethral hypermobility ${ }^{5-7}$ where two or three delayed or nonabsorbable sutures are placed 2-3cm lateral to the neck of the bladder through the endopelvic fascia and then through the ipsilateral Cooper's ligament and knotted in a tension free manner ${ }^{8}$. A $73 \%$ to $92 \%$ of "shortterm cure rate" which is defined as "the percentage with complete continence" and an $81 \%$ to $96 \%$ of "success rate" which is defined as "the percentage with cure or improvement" have been described in studies $^{9}$. The long term effectiveness and the success of the Burch colposuspension (5 to 10 years following the surgery) have been reported as continence in $70 \%$ of the patients ${ }^{9,10}$.

The laparoscopic approach for the Burch colposuspension was first described in the early $1990 \mathrm{~s}^{11}$. Several techniques have been introduced for the laparoscopic Burch colposuspension (LBC) where trans-peritoneal and extra-peritoneal approaches were the mainstay. The risk of pneumothorax and pneumomediastinum caused by excessive $\mathrm{CO}_{2}$ absorption is the main drawback in the laparoscopic extraperitoneal approach ${ }^{12,13}$. If another pelvic surgery is planned concomitantly along with the Burch colpo- suspension, the trans-peritoneal technique is more appropriate $\mathrm{e}^{14-18}$. Bladder mobilization has to be carried out in the trans-peritoneal approach which makes this technique more time consuming compared to the extraperitoneal approach ${ }^{17}$. Laparoscopic pelvic surgery carries many advantages since it provides optimal visualization intra-operatively and less pain, shorter hospital stay, better aesthetic results and quick return to day to day routine during the post-operative stage ${ }^{19}$. However, regardless of the benefits of the laparoscopic approach for the SUI repair, there are two schools of thought regarding the long-term efficacy of the laparoscopic Burch colposuspension as to whether it is effective or not in the long run ${ }^{19}$. Even though the evidence shows that the short-term success rate of laparoscopic approach is over $90 \%^{19,20}$, this rate falls to $59 \%-68 \%$ with longer follow-up ${ }^{20}$. There are several complications commonly associated with laparoscopic approach compared to the open Burch colposuspension. Myers et al has illustrated in his study that a higher rate of complications was associated with the laparoscopic Burch procedure (8-22\%) than the open approach (5-8\% $)^{21}$. Bladder and the lower urinary tract injuries are more common with the laparoscopic Burch colposuspension with an incidence of 2.17- 18\% which is much higher in patients with previous surgeries in the pelvis and the lower abdomen ${ }^{21}$. Comprehensive knowledge regarding the pelvic anatomy, expert and scrupulous dissection aids in the prevention of most of the bladder injuries. In expert hands, the majority of intra-operative complications can be managed laparoscopically rather than converting it to an open procedure ${ }^{22}$.

Currently, urinary incontinence is an under reported condition affecting mostly the elderly parous women with long term issues in their quality of life. Among those, Genuine Stress Incontinence (GSI) comprises of significant number of cases in Sri Lanka and globally. The laparoscopic approach is becoming more popular in Sri Lanka. The long-term outcomes and the patient's QOL assessment related to laparoscopic Burch colposuspension is lacking in the literature and this might be the first such study conducted in Sri Lanka.

The purpose of our study is to assess the effectiveness of the treatment and the quality of life at 6 and 12 months postoperatively among patients who underwent laparoscopic Burch colposuspension at Colombo South Teaching Hospital (CSTH), Sri Lanka. 


\section{Methods}

\section{Study design}

The study was conducted as a prospective cross sectional study at Colombo South Teaching Hospital, Sri Lanka.

\section{Recruitment and data collection}

In our study, 36 women aged 42 to 63 years with parity ranging one to five, who had undergone laparoscopic Burch colposuspension as a single procedure at Colombo South Teaching Hospital Sri Lanka during the period of 2016 to 2021 were studied. Laparoscopic Burch colposuspension was performed by an experienced operator on 36 women whose mean age was $54.3 \pm 4.7$ years. All of the study participants suffered from SUI or mixed urinary incontinence clinically. Thirty four percent of those women had undergone prior hysterectomies and 57\% of women were menopausal. None of them were smokers and all of them had no history of chronic cough. Patients with mix urinary incontinence undergo subtracted cysto-urethrogram in the standard way. Inclusion criteria included women with SUI clinically with or without failed conservative management. Patients with detrusor instability, patients who are medically unfit for laparos-copic surgery and patients with co-existing major degree pelvic organ prolapse needing repair surgery were excluded.

At the initial visit, thorough assessment was carried out with standardized medical and urogynaecological history, detailed examination, cough-stress test, urine full report and culture. All the patients who have fulfilled the inclusion criteria completed the "Short Urinary Distress Inventory (SUDI)" and "Short Incontinence Impact Questionnaire (SIIQ)" at the baseline and the post-operative follow-up period ${ }^{23}$. The SUDI questionnaire evaluates the symptom distress of urinary incontinence and the SIIQ questionnaire assesses the impact of incontinence on day to day activities. Data on recommencement of normal activities at the 3 months postoperative review were collected through standard questioning. A visual analogue scale was used to evaluate the patient satisfaction (visual analogue scale: $0-10$ where 10 signified being totally satisfied and 0 totally unsatisfied). The "Genito-Urinary Treatment Satisfaction Scale (GUTSS) ${ }^{24,25}$ " was used to assess the satisfaction with surgery at 6-month review. The range of the GUTS scale is 0 -32, where higher scores indicate greater satisfaction.

\section{Data analysis}

Unpaired Student's t-test was used to analyze normally distributed continuous variables while chi-square test or Fisher's exact test were used to compare the categorical variables. Six-month incidence of stress incontinence or detrusor over activity symptoms were analyzed using logistic regression. Stress urinary incontinence, urgency and urge incontinence symptoms at 12 months were evaluated using ordinal logistic regression. In order to increase the sensitivity, 12 month-incontinence symptoms were categorized into 'occasional' and 'frequent'. The independent $t$ test was used for comparisons between groups at the baseline and follow up visits. The dependent $t$ test was used for baseline analyses and the analysis of covariance (ANCOVA) was used for baseline or follow up by group analyses with the baseline scores entered as the covariate. A p-value of $<0.05$ was considered statistically significant.

\section{Results}

The preoperative characteristics of the patients are illustrated in Table 1. Six months following the surgery, SUI was $9.38 \%$ with $\mathrm{p}=0.38$, SUI and/or urge incontinence was $18.75 \%$ with $\mathrm{p}=0.56$, which were statistically not significant. Patient satisfaction was $88 \%$ with $\mathrm{p}=0.42$ (Table 2). Out of two women who had urge incontinence pre-operatively, only one continue to have the same issue post-operatively $(\mathrm{p}=0.67)$.

Table 3 shows the SUDI or SIIQ scales. The SUDI baseline score was $51.22 \pm 20.63$ versus $24.12 \pm 17.60$, while SIIQ score was $50.18 \pm 23.80$ versus $30.53 \pm$ 24.81 with $\mathrm{p}<0.01$. In both analyses, there were significant improvements in outcomes. Satisfaction with treatment outcomes from the GUTSS at 6 months follow up was $32.5 \pm 5.8$ with $\mathrm{p}=0.48$ where the maximum marks allocated for overall satisfaction was 34 (Table 4).

At 12 months following surgery, $15.6 \%$ of patients had GSI out of which $6.25 \%$ had it occasionally, while $9.38 \%$ had stress incontinence frequently $(\mathrm{p}=0.26)$. At 12 months, $18.75 \%$ had urgency where occasional urgency is recorded in $12.5 \%$ while $6.25 \%$ had frequent urinary urgency $(p=0.40)$. Occasional urge incontinence was existing in $9.38 \%$ patients, while $3.12 \%$ had it frequently ( $\mathrm{p}=0.38$ ) (Table 5). 
Table 1. The preoperative characteristics of population

\begin{tabular}{|l|c|}
\hline Variable & Laparoscopic Burch colposuspension \\
\hline $\begin{array}{l}\text { Age (years) } \\
\text { Mean (SD) }\end{array}$ & $53.3(4.7)$ \\
\hline $\begin{array}{l}\text { Parity } \\
\text { Mean (SD) }\end{array}$ & $2.6(1.2)$ \\
\hline $\begin{array}{l}\text { Weight (Kg) } \\
\text { Mean (SD) }\end{array}$ & $75.3(15.9)$ \\
\hline Urinary urgency symptoms/Urge incontinence (\%) & 6.25 \\
\hline
\end{tabular}

Table 2. Clinical evaluation of incontinence and patient satisfaction outcomes at 6 months following laparoscopic Burch colposuspension

\begin{tabular}{|l|c|c|}
\hline Variable & LBC & P value \\
\hline SUI (\%) & 9.38 & 0.38 \\
\hline SUI and/or Urge incontinence (\%) & 18.75 & 0.56 \\
\hline
\end{tabular}

(LBC): Laparoscopic Burch colposuspension

(SUI): Stress urinary incontinence

Table 3. Analysis of self-reported measures at baseline and 6 month follow up by treatment cohort

\begin{tabular}{|l|c|c|c|}
\hline Variable & Baseline & Follow up & P value \\
\hline SUDI & $51.22 \pm 20.63$ & $24.12 \pm 17.60$ & $<0.01$ \\
SIIQ & $50.18 \pm 23.80$ & $30.53 \pm 24.81$ & $<0.01$ \\
\hline
\end{tabular}

(LBC): Laparoscopic Burch colposuspension

(SIIQ): Short Incontinence Impact Questionnaire

(SUDI): Short Urinary Distress Inventory 
Table 4. Satisfaction with treatment outcomes at 6-months follow up: GUTSS scores

\begin{tabular}{|l|c|c|c|}
\hline Variable & Median & IQR & P value \\
\hline Satisfaction with outcome* & 17 & 4.3 & 0.48 \\
Satisfaction with care** & 15 & 4.3 & 0.66 \\
Overall GUTSS satisfaction*** & 32.5 & 5.8 & 0.48 \\
\hline
\end{tabular}

*Scale range: 02 to 18 . The higher the score, the greater the level of satisfaction.

**Scale range: 02 to 16 . The higher the score, the greater the level of satisfaction.

***Scale range: 02 to 34 . The higher the score, the greater the level of satisfaction.

(GUTSS): Genito-Urinary Treatment Satisfaction Scale; (IQR): Interquartile range.

Table 5. Satisfaction with treatment outcomes at 6 months follow up: GUTSS scores

\begin{tabular}{|l|c|c|}
\hline Variable & Laparoscopic Burch colposuspension & P value \\
\hline $\begin{array}{l}\text { Stress incontinence (\%) } \\
\text { Occasionally }\end{array}$ & $6.25 \%$ & 0.26 \\
Frequently & $9.38 \%$ & \\
Urinary urgency (\%) & $12.5 \%$ & 0.40 \\
Occasionally & $6.25 \%$ & \\
Frequently & & 0.38 \\
Urge incontinence (\%) & $9.38 \%$ & \\
Occasionally & $3.12 \%$ & 0.56 \\
Frequently & $88 \%$ & \\
Patient Satisfaction (\%) & & \\
\hline
\end{tabular}

*Frequently $\quad \geq 3$ episodes for 24 hours $\quad *$ Occasional < 3episodes for 24 hours

\section{Discussion}

Burch colposuspension is a long-lasting and effective surgical procedure for urinary stress incontinence ${ }^{6}$. The laparoscopic approach for the same procedure is becoming more popular worldwide due to its advantages such as minute incisions with better cosmesis enhanced visualization of the anatomy, easy access to the tissue planes, less intra-operative bleeding and quicker recovery and shorter in-ward stay in the postoperative period ${ }^{28}$. Many authors have illustrated that the success rate of laparoscopic Burch procedure is more or less similar to the cure rate acquired with open Burch technique, however, the follow-up duration was shorter in the laparoscopic approach ${ }^{12,29-31}$. 
Mean age of the population is 53.3 years which is similar to most of the study populations. However, premenopausal and post-menopausal both are included to the study. Our study showed $90.62 \%$ of success or cure rate of the laparoscopic Burch colposuspension procedure at the 6 months follow-up period which is similar finding to literature ${ }^{4,6,7,8}$. Urgency / Urge incontinence is a known complication following surgery. However only one patient continue to have Urgency / Urge incontinence in 6 and 12 months follow up. There is a significant improvement in patient satisfaction following surgery in 6 and 12 months follow up. Findings are comparable to literature ${ }^{24,25,26}$. The propensity of the surgeons to perform a laparoscopic Burch colposuspension surgery was partially affected by the introduction of the "Trans Vaginal Tape (TVT)" procedure. Studies comparing the outcomes and the pros and cons of the laparoscopic Burch colposuspension versus the TVT surgeries, were lacking and consisted of shorter duration of follow-up ${ }^{31,32}$. TVT insertion procedure is less time consuming, having a shorter learning curve compared to laparoscopic Burch colposuspension and also a minimally invasive procedure needing only a few equipment though it has several adverse effects. Many studies in the past demonstrated the long-term success rate of the TVT procedure and it has been the first line choice of surgery for the stress urinary incontinance $e^{6,7}$ until the National Health Service in England has placed a restriction on TVT procedure due to its significant adverse effects in mid-2018. Since then, surgeons are mostly left with Burch colposuspension where the procedure is carried out either openly or laparoscopically.

Open Burch colposuspension have proven to be an effective surgery for the SUI since early 1990s and many studies have illustrated its long-term durability and success rate ${ }^{5-8}$. Meanwhile in the recent past, laparoscopic colposuspension approach has developed as a treatment modality in an effort to minimize the morbidity related to the open Burch procedure and to achieve an equivalent success rate ${ }^{17,32}$. Capitan et al in their systematic review ${ }^{33}$ analyzed 55 trials that consisted of 5,417 participants who underwent open Burch colposuspension and demonstrated an overall success rate between $68.9 \%$ and $88.0 \%$. They stated that the overall cure rate represented by the urinary continence were about $85-90 \%$ within the first postoperative year which declined to $70 \%$ in five years following the treatment.
Even though more than 150 articles published on laparoscopic colposuspension, the long-standing outcomes of it are indeterminate as a result of shorter follow-up duration in most series. The Cochrane Incontinence Group stated that "the laparoscopic colposuspension may be as good as open colposuspension at two years post-surgery according to the currently available data in 2006"34-37. Doret et al illustrated that long term effects with laparoscopic Burch colposuspension are comparatively good but actually slightly lesser than the long term success rate published with conventional open technique. The effects of the learning curve and the surgical expertise, engaged with a developing technique (laparoscopic Burch colposuspension) are to be reflected when evaluating the results in the various studies ${ }^{37}$.

In our study, the follow-up duration was limited to 12 months and the study sample was smaller. The main reason for those limitations was the limited available surgical expertise and the facilities for the laparoscopic corrective surgery. However, future studies with larger sample population and long-term follow-up are required for better analysis of the cure rate and the outcomes of the laparoscopic Burch colposuspension.

\section{Conclusion}

Laparoscopic Burch colposuspension is an effective technique and treatment modality for urinary stress incontinence. Both objective and subjective evaluation of long-term outcomes and the patient satisfaction as well as the quality of life following laparoscopic corrective surgery at 6 and 12 months of follow-up demonstrated significant improvement and the repetitive corrective surgeries are uncommon.

\section{References}

1. Abrams P, Cardozo L, Fall M, Griffiths D, Rosier P, Ulmsten U, van Kerrebroeck P, Victor A, Wein A. The standardisation of terminology of lower urinary tract function: report from the Standardisation Sub-committee of the International Continence Society. Neurourol Urodyn 2002, 21: 167-78.

2. Jolleys JV. Reported prevalence of urinary incontinence in women in a general practice. BMJ 1988; 296: 1300-02.

3. Rortveit G, Daltveit AK, Hannestad YS, et al: Norwegian EPINCONT Study. Urinary inconti- 
nence after vaginal delivery or cesarean section. N Engl J Med 2003; 348: 900-7.

4. McDougall EM: Laparoscopic management of female urinary incontinence. Urol Clin North Am 2001, 28: 145-9.

5. Burch JC. Urethrovaginal fixation to Cooper's ligament for correction of stress incontinence, cystocele, and prolapse. Am J Obstet Gynecol 1961; 81: 281-90.

6. Alcalay M, Monga A, Stanton SL. Burch colposuspension: a 10-20 year follow up. Br J Obstet Gynaecol 1995; 102: 740-5.

7. Drouin J, Tessier J, Bertrand PE, Schick E. Burch colposuspension: long-term results and review of published reports. Urology 1999; 54: 808-14.

8. Farzaneh Sharifi-Aghdas. Surgical Management of Stress Urinary Incontinence. Journal of Urology 2005; 2(4): 175-82.

9. Martin Dunitz; Cardozo L, Staskin D, Petri E. Retropubic cystourethropexies. In Textbook of female urology and urogynaecology. $1^{\text {st }}$ edition. London: 2001: 513-24.

10. Eriksen BC, Hagen B, Eik-Nes SH, Molne K, Mjolnerod OK, Romslo I: Longterm effectiveness of the Burch colposuspension in female urinary stress incontinence. Acta Obstet Gynecol Scand 1990; 69: 45-50.

11. Jelovsek JE, Barber MD, Karram MM, Walters MD, Paraiso MFR: Paraiso Randomised trial of laparoscopic Burch colposuspension versus tensionfree vaginal tape: long-term follow up. $\mathrm{Br} \mathrm{J}$ Obstet Gynaecol 2008; 115: 219-225.

12. Cooper MJ, Cario G, Lam A, Carlton M: A Review of results in a series of 113 laparoscopic colposuspensions. Aust N Z J Obstet Gynecol 1996; 36: 44-8.

13. Wolf JS, Monk TG, McDougall EM, McClennan BZ, Clayman RV. The extraperitoneal approach and subcutaneous emphysema are associated with greater absorption of carbon dioxide during laparoscopic renal surgery. Journal of Urology 1995; 154: 959-63.

14. Liu CY, Paek W. Laparoscopic retropubic colposuspension (Burch procedure). J Am Assoc Gynecol Laparosc 1993; 1: 31-5.

15. Brenner B. Comparing the laparoscopic Burch colposuspension and the suburethral sling. $\mathrm{N} \mathrm{Z}$ Med J 2001; 114: 146-8.
16. Fatthy H, El-Hao M, Samaha I, Abdallah K. Modified Burch colposuspension: laparoscopy versus laparotomy. J Am Assoc Gynecol Laparosc 2001; 8: 99-106.

17. Liu CY. Laparoscopic retropubic colposuspension (Burch procedure): a review of 58 cases. J Reprod Med 1993; 38: 526-30.

18. Lobel RW, Davis GD. Long-term results of laparoscopic Burch urethropexy. J Am Assoc Gynecol Laparosc 1997; 4: 341-5.

19. Lobel RW, Davis GD: Long-term results of laparoscopic Burch urethropexy. J Am Assoc Gynecol Laparosc 1997; 4: 341-5.

20. McDougall EM, Portis A. The laparoscopic bladder neck suspension fails the test of time. Journal of Urology 1999; 161: 105, Abst 393.

21. Myers DL, Peipert JF, Rosenblatt PL, Ferland RJ, Jacobson ND. Patient satisfaction with laparoscopic Burch retropubic urethropexy. J Reprod Med 2000; 45: 939-43.

22. Radomski SB, Herschorn S. Laparoscopic Burch bladder neck suspension: early results. Journal of Urology 1996; 155: 515-8.

23. Uebersax J, Wyman J, McClish D, Shumaker F, McKlish J, Santl J. Short forms to assess lifequality and symptoms distress for urinary incontinence in women; the Incontinence Impact Questionnaire and the Uro-Genital Distress Inventory. Neurourol Urodyn 1995; 14: 131-9.

24. Cornish A, Fynes M, Harmer C, Hawthorne G, Rosamilia A, Carey M, et al. The Genitourinary Treatment Satisfaction Score for continence surgery. Neurourol Urodyn 2001; 20:506-7.

25. Hawthorne G, Harmer C. GUTSS. The GenitoUrinary Treatment Satisfaction Scale Study. Melbourne, Australia: Centre for Health Program Evaluation; 2000, Working Paper N117. Prezioso et al. BMC Surgery 2013; 13(Suppl 2):S38 http:// www.biomedcentral.com/1471-2482/13/S2/S38

26. Tamussino KF, Zivkov F, Pieber D, Moser F, Haas J, Ralph G. Five-year results after anti-incontinence operations. Am J Obstet Gynecol 1999; 181: 1347-52.

27. Ross JV. Laparoscopic Burch repair compared to laparotomy Burch for cure of urinary stress incontinence. Int Urogynecol J 1995; 6: 323-8. 
28. Bezerra CA, Machado MT, Juliano RV, Ruano JMC, Barbosa CP, Borreli M, et al. Laparoscopic Burch surgery in public institution; cost comparative analysis. J Bras Urol 1999; 25: 68-72.

29. Miklos JR, Kohli N: Laparoscopic paravaginal repair plus Burch colposuspension: Review and descriptive technique. Urology 2000; 56(Sup 6A): 64-9.

30. Papasakelariou C, Papasakelariou B: Laparoscopic bladder neck suspension. J Am Assoc Gynecol Laparosc 1997; 4: 185-8.

31. Lobel RW, Davis GD: Long-term results of laparoscopic Burch colposuspension. J Am Assoc Gynecol Laparosc 1998; 91: 55-9.

32. Moehrer B, Carey M, Wilson D: Laparoscopic colposuspension: a systematic review. Eur J Obstet Gynecol Reprod Biol 2003; 110: 230-5.

33. Lapitan MC, Cody DJ, Grant AM: Open retropubic colposuspension for urinary incontinence in women. Cochrane Database Syst Rev 2003; 3: 217-19.

34. Persson J, Teleman P, Eten-Bergquist C, WolnerHanssen P. Cost analyses based on a prospective, randomised study comparing laparoscopic colposuspension with a tension-free vaginal tape procedure. Acta Obstet Gynecol Scand 2002; 81: 1066-73.

35. Vancaillie TG, Schuessler W. Laparoscopic bladder neck suspension. J Laparoendosc Surg 1991; 1: 169-73.

36. Dean NM, Ellis G, Wilson PD, Herbison GP. Laparoscopic colposuspension for urinary incontinence in women. Cochrane Database Syst Rev 2006; 3: 245-7.

37. Doret M, Golfier F, Raudrant D. Laparoscopic retropubic colposuspension (Burch procedure). Techniques and continence results. J Gynecol Obstet Biol Reprod 2000; 29(7): 650-4. 